\title{
The Impact of Housing Economy on China's Economic Development During the COVID-19: Based on the Perspective of Data Analysis
}

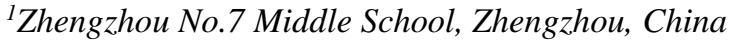 \\ ${ }^{2}$ Chengdu Shude high school, Chengdu, China \\ ${ }^{3}$ New Oriental Academy, Beijing, China \\ * Corresponding author: guanghua.ren@gecacademy.cn \\ These authors contributed equally.
}

Yifei Song ${ }^{1, \dagger}$, Zile Wang ${ }^{2, \dagger}$, Xinyu Zhu ${ }^{3,, \dagger}$

\begin{abstract}
Contemporarily, the COVID-19 has greatly affected the China's economic development. Based on the perspective of data analysis, this paper impacts of housing economy during COVID-19 discussions about the effects on daily life and economic situation. Specifically, the descriptive research method is utilized to analyse. For the sake effective and accurate, effective information is selected from various platforms, e.g., China News, Shenzhen News, NCPSSD, etc. Based on the results, the online learning education platform and online conference application developed rapidly during the epidemic period in China. Furthermore, with the rapid development of online game industry during the epidemic period, China's e-commerce has also become a trend. Overall, the impacts of the epidemic on China's economy and people's lives are demonstrated. These results provide novel understanding of the housing economy and pave new paths for the future development of enterprises.
\end{abstract}

Keywords: Housing Economy; COVID-19.

\section{INTRODUCTION}

\subsection{Research Background and Motivation}

In the past 2020, the outbreak of COVID-19 has ravaged whole world, which has a certain negative impact on the development of human civilization from the environment, physiology, psychology, etc. Historically, major events have not only brought negative effects to the economy, but also accelerated the upgrading of related industries. For example, the financial crisis in the United States in 1928 gave birth to chain supermarkets; the SARS epidemic in 2003 gave birth to a number of online retail giants (e.g., Alibaba). The novel coronavirus pneumonia is also a "catalyst" for both "epidemic" as well as the evolution and transformation of the retail industry. It will accelerate the rise of the new retail mode and bring new opportunities to consumer retail. The outbreak of the epidemic has once again stimulated the housing economy. Obviously, COVID-19 has caused huge cost and losses to the economies of countries all over the world. Many countries faced serious problems that there is a lack of goods and materials to support people's daily life and the country's normal operation. However, Chinese turnover materials and carry out regular consumption better in such a period, which minimized the impact of economic recession in the short term. Ride out the crisis safely is attributed to the rapid development of housing economy. According to previous studies, the housing economy can be divided into three categories: the express industry, mobile video game and education industry, and e-commerce, online medical as well as office industry.

Based on iResearch's survey data, the scale of China's catering takeout industry in 2019 will be 653.6 billion yuan, an increase of 39.3\% compared with 2018 . By the end of 2019, there are about 460 million takeout consumers among China's 900 million Internet users, with a year-on-year growth of $12.7 \%$. The order volume and transaction amount also maintained a rapid growth Besides, during COVID-19, online entertainments (e.g., $\mathrm{TV}$ dramas and video games) support a large part of the 
economic circulation. In general, people's way of life has been greatly affected. Most people spend more time at home and change their consumption habits as well as entertainment lifestyle, which converts from shopping and travelling to online shopping and games. In this case, People's life depends more on media and internet. This is also the fundamental driving force to promote China's housing economy. During the epidemic period, the impact of housing economy is not only reflected in the change of people's lifestyle, but also reflected in the "concept stock of housing economy". According to the statistics of securities times data, as of midday, the concept of "housing economy", which focuses on cloud office, cloud games and online education, was significantly ahead of the new segment. 94 concept stocks in the last four trading days (February 4 to February 7) have increased by more than $20 \%$ on average, greatly outperforming the market. The current market value is nearly 220 billion yuan higher than that of February 3. Half of the stocks rose by more than $40 \%$ in the past four years, and eight stocks were listed on the quadruple board. Additionally, cloud game concept stocks Jinke culture are also strong on the quadruple board.

\subsection{Literature Review}

Before the outbreak of the COVID-19, the scholars did not have a lot of research on housing economy. Most of them start their research with the development trend of housing economy and focus on the analysis of the current social phenomenon. Meanwhile, it puts forward some guiding suggestions for the development of housing economy at that time $[1,2]$. The development of housing economy is closely related to the present and future of many industries, (e.g., ecommerce, cosmetics, etc.). Besides, a socially recognized conclusion is that the development of the housing economy will be further promoted in the next few years due to the rapid development of the network society and the continuous growth of the Internet world [3].

Compared with before the outbreak of the epidemic, the research on housing economy has increased significantly during and after COVID-19. More scholars and investors focus on this economic source that has been rarely developed. A large amount of studies focused on the changes of people's lifestyles and the development of related housing economy during the outbreak of the epidemic, as well as the evaluation of its advantages and disadvantages. For example, online shopping, fresh e-commerce, online health care, online education, online office and other economic formats are relatively active, making "housing economy" an important economic development mode. According to the statistics of iiMedia Research, $21.3 \%$ of home Internet users' online consumption accounts for more than $61 \%$ of the total consumption in 2019. Moreover, home Internet users are highly dependent on online consumption, where $77.1 \%$ of the netizens mainly use online channels for entertainment. Although some groups (e.g., conservative catering industry) are not optimistic about the development of residential economy due to the current online service drawbacks and issues, most groups are optimistic about the housing economy. Electronic trading volume skyrocketed by $350 \%$, which become the most typical representative of the "era of house economy". Nevertheless, the supply of personnel in e-commerce enterprises is insufficient with the continuous development of the residential economy model, while the catering industry staff has a restriction phenomenon [4-6].

\subsection{Research Contents}

Anyway, there is not enough analysis about the development and effect of housing economy after the COVID-19. On this occasion, the impacts of housing economy on economic development are investigated after the outbreak of the epidemic in this paper. Primarily, the current development status of housing economy is introduced. Then comparison and analysis have been carried out for the specific changes of housing economy before and after the outbreak of the COVID-19. Subsequently, the specific aspects of housing economy that affect economic development are explored. Finally, according to the analysis, the sustainable development countermeasures of housing economy in the later epidemic era are putting forward, promoting the development of housing economy to a certain extent. This rest part of the paper is organized as follows: The second part is the analysis combined with the relevant data. The third part is the result and discussion of data analysis. The fourth part is the conclusion.

\section{METHODOLOGY}

This research is based on a theoretical social concept, including mass consumption behavior, various service developments, and consumer groups, i. e., most of the collected information will be descriptive. Therefore, teh research design will be qualitative rather than quantitative. In addition, further research and analysis are carried out deeply based on the secondary sources. Moreover, it will not be able to carry out the research in a simple way through the correlational research. The reason is that this research is going to contribute a specific analysis of the economic development and trend of a wide range of different industries under the residence economy and explain the impact on people's lifestyle. Thus, in order to ensure the feasibility of the study and accuracy of the research results, the descriptive research method will be used. 


\subsection{Data Sources}

The utilized websites and platforms are mainly China News, Shenzhen News, Sina Finance, National Center Philosophy and Social Sciences Documentation (NCPSSD). Since our research is aimed at housing economic development, information is collected from local Chinese websites, where the main representative of Chinese websites is China News. Besides, Sina Financeis also an excellent utizlied sorce, which provides more extensive and plentiful data and information that are easier to understand and arrange. It is worth mentioning that National Center for Philosophy and Social Sciences Documentation is an effective website that offers more theoretical and professional previous studies as a reference for further study.

\subsection{Data Analysis}

Generally, the impact of residence economy on China is huge in the field of network distance learning. According to China News, many Chinese enterprises have launched the online office mode during the period of epidemic prevention and control. The remote office softwares (e.g., "Lark", "DingTalk", "Xiaoyu Yilian", "Tencent meeting") are used to take into account both home isolation and online work for most enterprises [7]. Shenzhen News concludes that online learning offers people a variety of choices. The concept of online education continues to gain momentum in China despite the delay in the opening of classes during the epidemic [8]. The continuous improvement of users' acceptance of online education, the gradual cultivation of online payment awareness and the improvement of online learning experience and effect will be the main reasons for the continuous growth of online education market size.

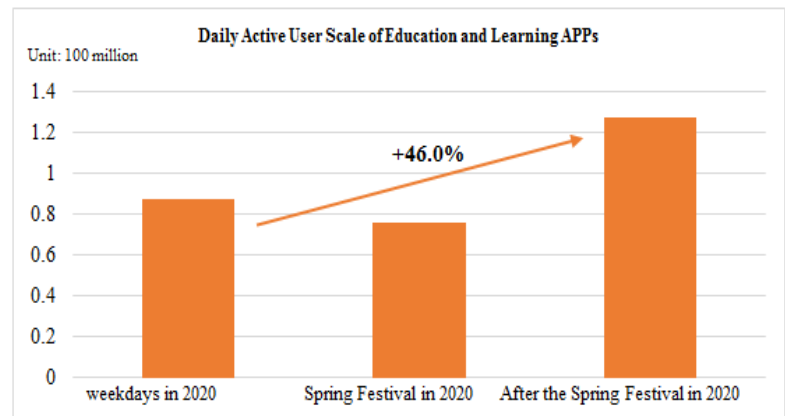

Fig.1. The growth of active users of online education apps around the Spring Festival in 2020 in China

Figure 1 shows the growth of active users of online education apps in China before and after the Spring Festival in 2020. It can be seen from the figure that the activity of online education apps is high during the Spring Festival.

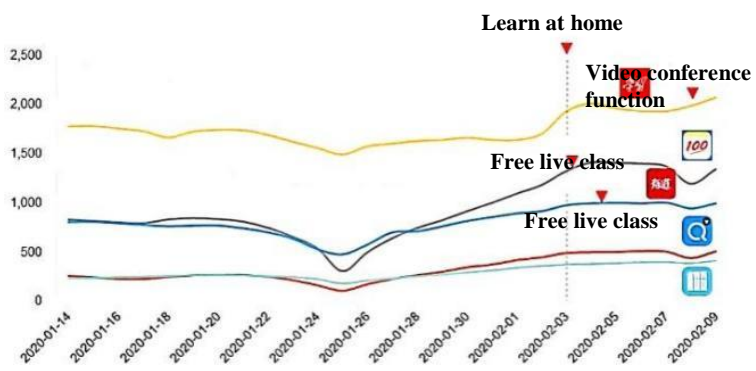

Fig.2. Trend of active users in Education Department apps before and after the Spring Festival holiday in 2020 in China

Furthermore, we can see from Figure 2 the trend of active users of the app of the Ministry of education before and after the Chinese New Year in 2020 that the number of users of online education software has increased sharply since the beginning of school in February 2020.

What's more, because of the epidemic, China's online shopping is particularly active because of the epidemic. Due to the influence of COVID-19, Chinese people stay indoors during the Spring Festival, and their consumption power and demand are converted to online commodity consumption. According to sohu.com, sales of fresh fruits, leisure snacks, chess and card entertainment also rose sharply during the epidemic. At the same time, more than 30,000 people opened new shops on the Taobao app every day in February 2020, according to data. According to Tmall International, demand for imported kitchen appliances, food ingredients and other products has increased significantly since the start of the 2020 Spring Festival holiday [9]. In addition, under the influence of the epidemic, offline production has been affected to a certain extent, and all people are basically "staying" at home, so in this case, e-commerce has become the main consumption channel at present. In order to actively respond to the national first-class health prevention and control policy, people began to reduce the frequency of going out to buy vegetables, and began to buy vegetables online instead of going out. According to the analysis of relevant research data, during the Spring Festival epidemic prevention in 2020, the trading volume of fresh e-commerce soared by $350 \%$, and the fresh e-commerce has become the most typical representative of the "housing economy era during the Spring Festival epidemic prevention in 2020."[10]. 


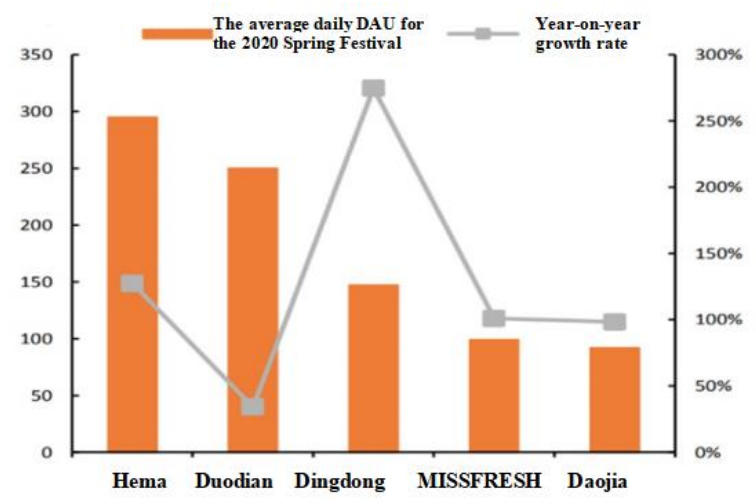

Fig.3. The number of daily active users of online vegetable shopping apps during the Spring Festival in 2020

As can be seen from the Figure 3, during the daily average DAU of Freshhema was the highest among several comparative data, nearly 3 million yuan. And Dingdong had the highest year-over-year growth rate at practically $300 \%$. This shows that the e-commerce platform has achieved rapid growth during the epidemic period.

However, it is worth paying attention to that, with the continuous development of the residential economy model, the supply of personnel in e-commerce enterprises is insufficient with the continuous development of the residential economy model, while the catering industry staff has a restriction phenomenon. Last but not least, the stowaway economy during the epidemic brings new opportunities for games and entertainment. On March 4, 2020, Thunderbird Technology, a subsidiary of TCL Electronics, officially released the data report of TCL TV during the Spring Festival holiday. The report shows that during the period from January 24 to February 23, 2020, the average daily on-screen time of TCL TV reaches 7.9 hours, and the number of TV members has increased by $177 \%$ year-on-year. In addition, users of Inke's online dating APP Duiyuan surged by $300 \%$ during the Spring Festival. Moreover, during the outbreak of the epidemic in early 2020, the number of mobile online game users surged, which is a significant phenomenon [11].

Daily active users of some mobile game apps

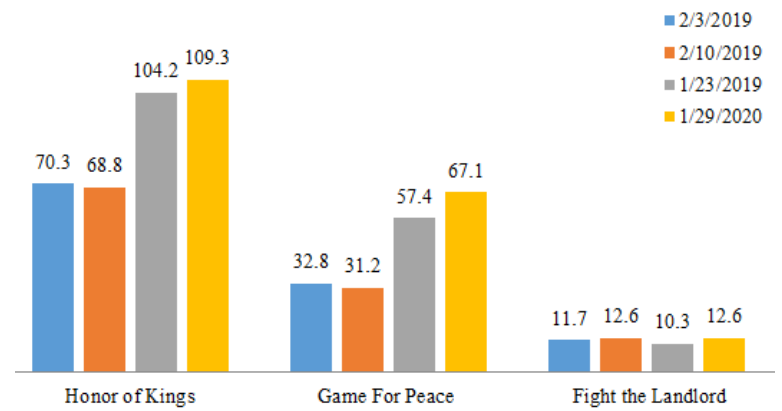

Fig.4. Daily active users of some mobile game apps during the Spring Festival in 2019-2020
As seen in Figure 4, the number of daily active users of Honor of King and PUBG have increased significantly. Comparing with the data of the same period last year, the number of daily active users of Honor of King has increased $55 \%$, and the number of daily active users of PUBG has doubled 104\%. The difference between Fight the Landlords and last year's data is not much, almost the same. At the same time, we found that with the extension of time people staying at home during the epidemic, the daily active users of Honor of Kings and PUBG dropped by about ten percent. It can be seen that although the prolonged time at home caused by the epidemic gave the game market a good opportunity, it is not durable. A small number of people just started playing games on a whim because they were bored at home, and it did not take long because they are not interested in it themselves; most people did not have time to spend time playing games eventually after the epidemic became better and they started going to school or work.

In addition to the rapid developments of industries and aspects mentioned above that rapidly rising due to the development of housing economy in the epidemic, some other industries are also well promoted, such as express delivery industry, online medical care, online short video and so on. Innovative business models, innovative business environment and more innovative technologies are all important factors to effectively promote the development of China's residential economy. There is no doubt that from the current situation, all aspects of "house economy" development trend is good, and it is expected that online low cost, quick response and other advantages, offline outlets will accelerate the shrinkage [12].

\section{RESULTS AND DISCUSSION}

According to the above data, online education, online office, online shopping and e-commerce all increased significantly during the epidemic period due to the rapid growth of the housing economy. There is no doubt that from the current situation, the housing economy in all aspects of the developing trend is positive, is expected that the low cost of online shopping, fast response and other advantages will accelerate the shrinkage. It is true that some pointed out that teenagers use electronic products need to be accompanied by adults and other drawbacks so forth. However, according to the current situation, housing economy is only a new way of "Internet Plus", which has never meant to abandon off-line behavior.

In the above paper, data we have collected and analyzed in detail from the different aspects of the geek economy that may have an impact on people's lives, and we have also compared the data is given horizontally and vertically come up with corresponding results. First of all, plenty of learning software are utilized with the 
rapid development of the Internet, especially after the outbreak of the new crown epidemic, applications such as "Lark", "DingTalk", "Xiaoyu Yilian", "Tencent meeting" and other learning software. The number of users of online educational software showed a sharp increase at the beginning of February 2020, when school resumed.

Secondly, the e-commerce platform grew rapidly during the epidemic. Due to the inability to leave home, the the traditional offline purchase of fresh vegetables in the past shift from to online shopping, online payment, and then offline delivery.

Finally, the epidemic has allowed the gaming and entertainment industry the opportunity to grow rapidly in a short time. Mobile games should grasp the opportunity to develop more diverse gameplay, research customers and target the core market to decide their future development direction.

\section{CONCLUSION}

In order to prevent the further deterioration of the epidemic situation, China has issued the policies such as city closures, requires residents to stay at home as far as possible. Therefore, the concept of housing economy has been widely concerned. We also wants to know the impact of housing economy on China's economic development during the period of COVID-19. Based on the analysis, global economic development has encountered obstacles due to the outbreak of the epidemic, to a certain extent.

First of all, after the outbreak of the epidemic, online learning education platform and online conference apps have developed rapidly. Thus, the economic losses caused by the suspension of work and school are alleviated. Secondly, the e-commerce platform grew rapidly during the epic. This also supports the sustainable economic development of major enterprises. At the same time, we have developed more modern and updated marketing methods have been developed. Even after the epidemic has been effectively controlled, e-commerce has become a trend. Thirdly, housing economy has allowed the gaming and entertainment industry the opportunity to grow rapidly in a short time. Therefore, we suggest that mobile games should grasp the opportunity to develop more diverse gameplay, research customers and target the core market to decide their future development direction. The concept of housing economy is popularized to the public and guide people to clearly understand and recognize the development status and future trend of housing economy. At the same time, this article also hopes to provide some enterprises or online platforms with the development ideas of e-commerce, which has helped to promote the progress of housing economy.

\section{REFERENCES}

[1] Li Wenming, Lu Fuyu. The development and guiding strategy of "house economy". Academic exchange 000.011 (2014): 112-116.

[2] $\mathrm{Li}$ Juxing. On the housing economy and its influence. China ASEAN Expo 11 (2013): 73-74.

[3] Jiang ting. "Home economy" promotes the upgrading of e-commerce consumption. People's forum no.684.29 (2020): 86-87.

[4] Qi Xiaoying. Housing economic development and improvement in China during the epidemic period."China Economic and Trade Guide (2) (2020).

[5] MagReaderHD-NFC (2020). The housing economy under the influence of epidemic situation, No. 6 , 2020 .

[6] Q. H. Hou (2020). Study on the development of residential economy under the influence of COVID-19, Theoretic Observation, No. 03, 2020, p. 12.

[7] China News) 2020). New "housing economy" und er COVID-19: New development opportunities. htt ps://baijiahao.baidu.com/s?id=1658524220741001 $589 \& w f r=$ spider $\&$ for $=p c$

[8] Shenzhen News (2020). House economy in the epidemic ushered in the outbreak. https://baijiahao.baidu.com/s?id=16582870960662 $29437 \& w f r=$ spider $\&$ for $=p c$

[9] Z. S. Xie (2020). Research on network "house economy" and development trend under epidemic situation, The Chinese market, No. 26, 2020, p. 10. http://ncpssd.org/Literature/readurl.aspx?id=71026 77362\&type $=1$

[10] Q. H. Hou (2020). Study on the development of residential economy under the influence of COVID-19, Theoretic Observation, No. 03, 2020, p. 12. http://ncpssd.org/Literature/readurl.aspx?id=71015 80664\&type $=1$

[11] Sina Finance (2020). Housing economic growth under the epidemic situation. http://finance.sina.com.cn/stock/relnews/cn/202003-04/doc-iimxxstf6437335.shtml.

[12]Z. S. Xie (2020). Research on network "house economy" and development trend under epidemic situation, The Chinese market, No. 26, 2020, p. 11. http://ncpssd.org/Literature/readurl.aspx?id=71026 77362\&type $=1$. 